\title{
The specification and design of an interactive virtual environment for use in teacher training
}

\author{
Fiona French,* lan Cumpson** and Ruth Wood*** \\ *University of North London, **University of Greenwich \\ ***Kingston University \\ email:f.french@unl.ac.uk
}

In this paper, we examine the rationale behind the specification and design of an interactive, virtual environment, optimized for particular task-based learning activities and the dissemination of information. The software we describe represents a typical British primary school, for use in training Information and Communications Technology (ICT) co-ordinators at primary level. By documenting our ongoing evaluation of both this resource and the technologies used in its implementation, we provide a detailed description of the production process of a prototype piece of software. This highlights the importance of pedagogy, new technologies and project management, and should be of particular interest to multimedia designers and academics preparing to develop innovative learning applications.

\section{Introduction}

The original concept was to create a 'simulation' which would provide trainee teachers, specializing in Information and Communications Technology (ICT) with the opportunity to explore a primary school environment. Within the simulation, factors affecting the development and implementation of ICT would be modelled so that trainees would be able to develop the skills, knowledge and understanding necessary to identify appropriate strategies to overcome the limitations. To this end, we have developed Allsorts Primary the prototype of a simulated interactive environment, representing a typical primary school.

The application is accessible via the Internet and presents the user with a virtual school that can be examined room by room, using the mouse or keyboard. There are thirteen members of staff in the school, and users can watch pre-recorded video interviews with 
these people, as well as reading all the paper documentation that relates to their enquiries and is normally found on the premises. Figure 1 shows a snapshot of a classroom in the virtual school.

Figure 1: Allsorts Primary classroom.

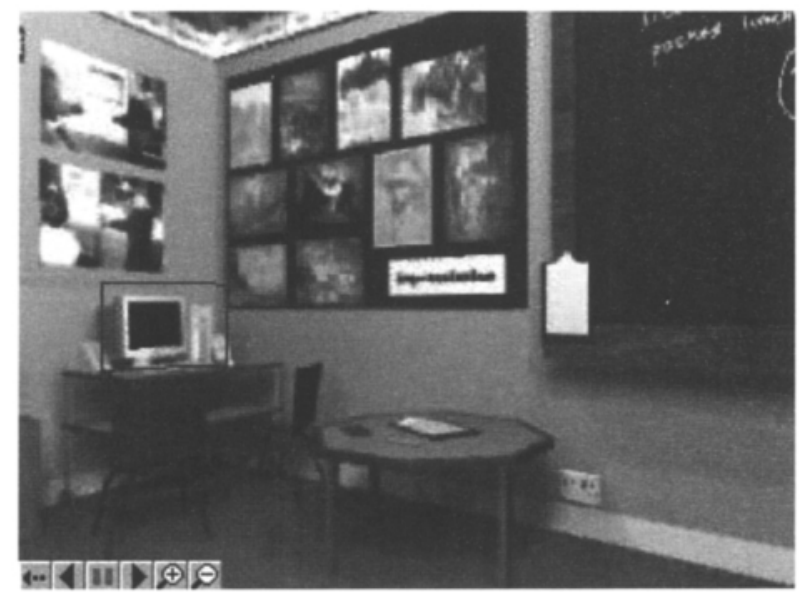

In this paper we will explain the reasons behind making certain fundamental decisions regarding the nature of this software as well as providing a detailed description of the production process, following the stages of our design to show how we reached conclusions. The aim is to provide an overview of the development lifecycle of a bespoke learning resource, demonstrating the fusion of pedagogical aims, interface design principles and state-of-the-art technology. The process was collaborative and iterative, with the actual specification and design of the software running in parallel, one informing the other. A comprehensive evaluation of the finished product will be carried out later in 2001 by second year B.Ed. students at the University of North London and by a focus group at Kingston University, whose feedback and learning experience will be reported separately.

\section{Specification}

\section{Rationale}

All B.Ed. students attending the University of North London choose a specialist subject to study on completion of their first year in initial teacher training for the primary phase. The specialist pathway consists of five modules, and for ICT specialists, the last of these focuses on the role of the ICT co-ordinator.

Any subject co-ordinator is expected to produce documentation such as policies and schemes of work which identify how the subject is viewed and taught within the school. In addition to this, issues central to the role of a co-ordinator include staff training, purchase and allocation of new resources, monitoring and evaluating the provision, delivery and assessment of the subject area in question, as well as planning for future developments (Briggs, 1997: 5). Organizational and communication skills are clearly necessary and, perhaps more importantly, interpersonal skills in order to develop a shared goal amongst the staff within the school. The co-ordinator of any subject faces a complex role. 
For the ICT co-ordinator, this role may be more challenging because of the diversity of staff expertise, attitudes and range of equipment within the school. As it is a crosscurricular subject, it is necessary for the ICT co-ordinator to communicate effectively with other subject co-ordinators: ICT cannot be taught in isolation.

The fast-developing area of ICT requires a substantial amount of time devoted to learning about new technologies and their impact upon teaching and learning (Harrison, 1998: 10). Consequently, using multimedia technology to provide some of the resource material for this subject area is very appropriate. Trainees will be expected to regard the software critically and provide useful feedback for the developers.

The final module for ICT specialists aims to address the skills, knowledge and understanding necessary for the successful co-ordination of this curriculum area. It is difficult to control the learning experiences of trainees, who are placed in schools where time is scarce and there may be unwillingness on the part of the staff to discuss a sensitive issue. While in some respects, it could be argued that this is the 'real world experience', inappropriate or inadequate placements could also be detrimental to the trainee's development as a potential co-ordinator of ICT.

Allsorts Primary aims to alleviate this problem by offering all trainees the same school environment and ample opportunity to discuss the issues affecting the development of ICT within that school. Thus, it incorporates key aspects of Laurillard's teaching-learning model (Laurillard, 1994): the discussion of relevant concepts involving tutor and trainees; a 'tutor-constructed world' designed to initiate reflection; trainees' interaction with this and subsequent experiential knowledge. In addition, electronic delivery enables trainees to interact with the resource from a distance. Therefore, they can take their time to browse the virtual school in the role of an ICT co-ordinator, interacting with various media in order to assess the current situation without the unrealistic pressure of performing under scrutiny in a classroom. This should provide them with the necessary data to construct an ICT development plan for the whole school.

\section{Tutor's brief}

The original concept of an interactive, virtual school stems from a need to create a controlled learning environment where trainee co-ordinators can explore schools with predetermined specifications. It involves creating a range of teacher personalities and a variety of school environments. The intention is to select from a 'resource bank' of teachers and schools in order to generate complex situations which currently exist in primary schools in terms of ICT. By being able to select the variables, for example 'teacher attitude towards information technology", the tutor can direct the attention of the trainees to the specific skills, knowledge and understanding required for the successful co-ordination of ICT.

The use of visual and audio cues is important in order to make the experience as realistic as possible whilst reflecting Gardner's theory of multiple intelligence by using a variety of stimuli to support learning (Gardner, 1993). Data presented through such media carries more information, for example, facial expression, intonation and non-verbal communication.

To simulate the role of the co-ordinator, the trainee needs to interact with the staff by asking questions and exploring the school to examine the provision for ICT in terms of available software and hardware. Furthermore, if the trainee can investigate the equipment in each 
classroom to determine whether it is in working order and the amount of use it has had, it will provide a more complete picture of the implementation of ICT within the school.

By providing access to such a resource outside directed teaching time, the possibilities of employing a variety of teaching approaches becomes more realistic. Trainees can return to the resource whenever they have access to the Internet and interview staff as many times as they want. During taught sessions, the tutor can organize the trainees into pairs, groups or request that they work independently. The role of the software is not that of a tutor but as a resource which enhances the teaching and learning experience. Trainees are able to take control of their own learning, interacting with the data presented and scaffolding their own learning through discussions related to the school simulation (Vygotsky, cited in Ager 1998: 18; Tiffin and Rajasingham, 1995: 54). The focus, therefore, is on what they learn rather than what they remember (Ramsden, 1992: 41).

Interviews can be repeated, rooms revisited and tasks redone as many times as required. Figure 2 shows a still from a video interview. Trainees are expected to make notes on paper in real time as they explore the school, just as they would in real life. Ideally, the program should keep track of the trainee's movements, so that teachers in the school appear to know if the user is interviewing them for the first time, in which case an introductory greeting occurs.

Figure 2: Interview with a member of staff.

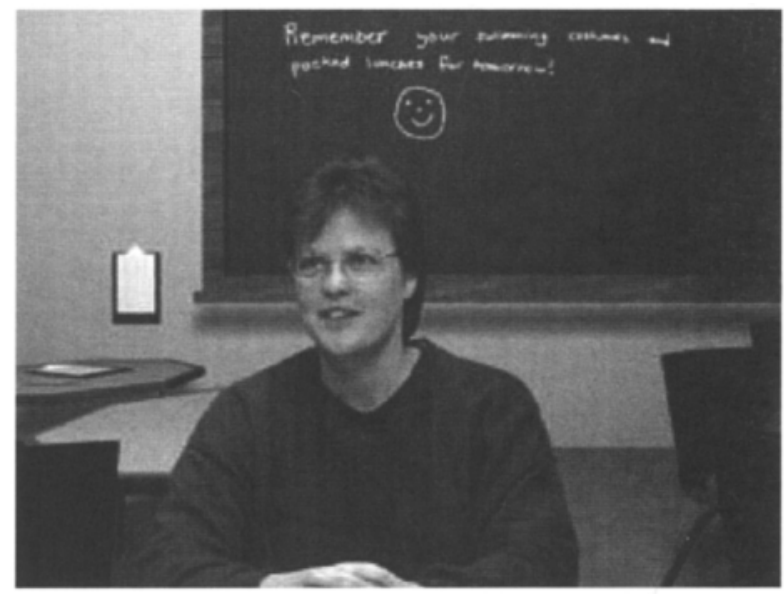

The school also features some random and apparently spontaneous incidents; for example, periodically a small boy tears past and rushes out into the playground. There is a background soundtrack taken from a real school environment. Trainees can also interview children in each class. The documentation sometimes has coffee stains that enhance realism and the sense that the paper has been passed around the staff room.

\section{Design criteria}

The creation of an original piece of multimedia courseware requires thorough and rigorous planning in order to make best use of available resources, such as hardware, software, skills and knowledge. These are some of the issues that arose and questions that we asked ourselves. 


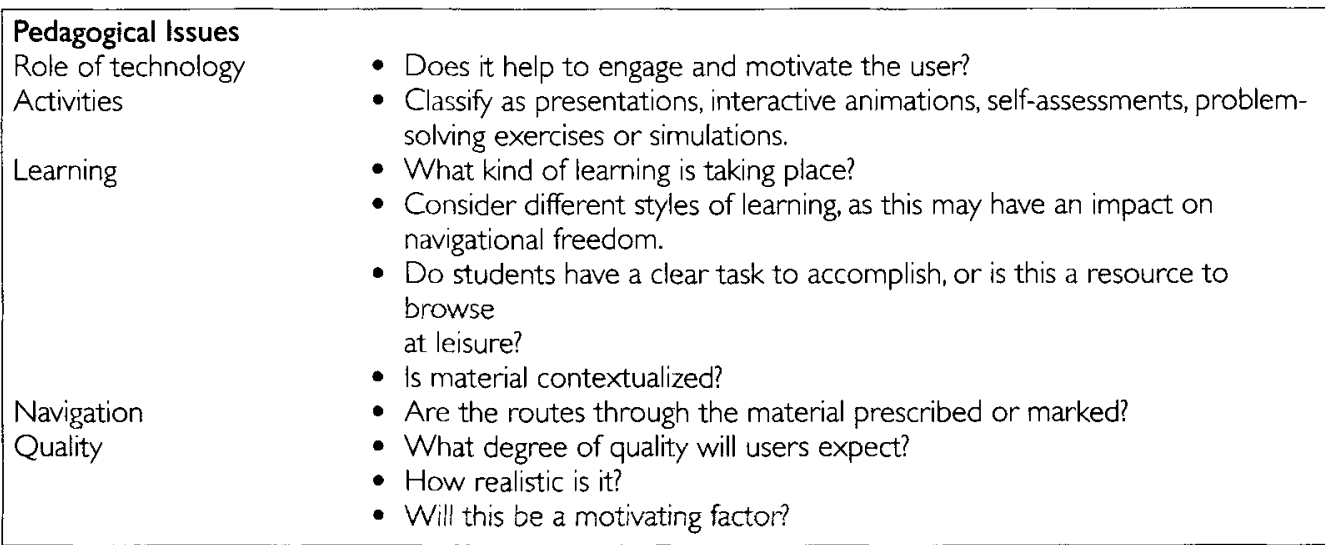

Table 1: Some pedagogical considerations for interactive learning resources.

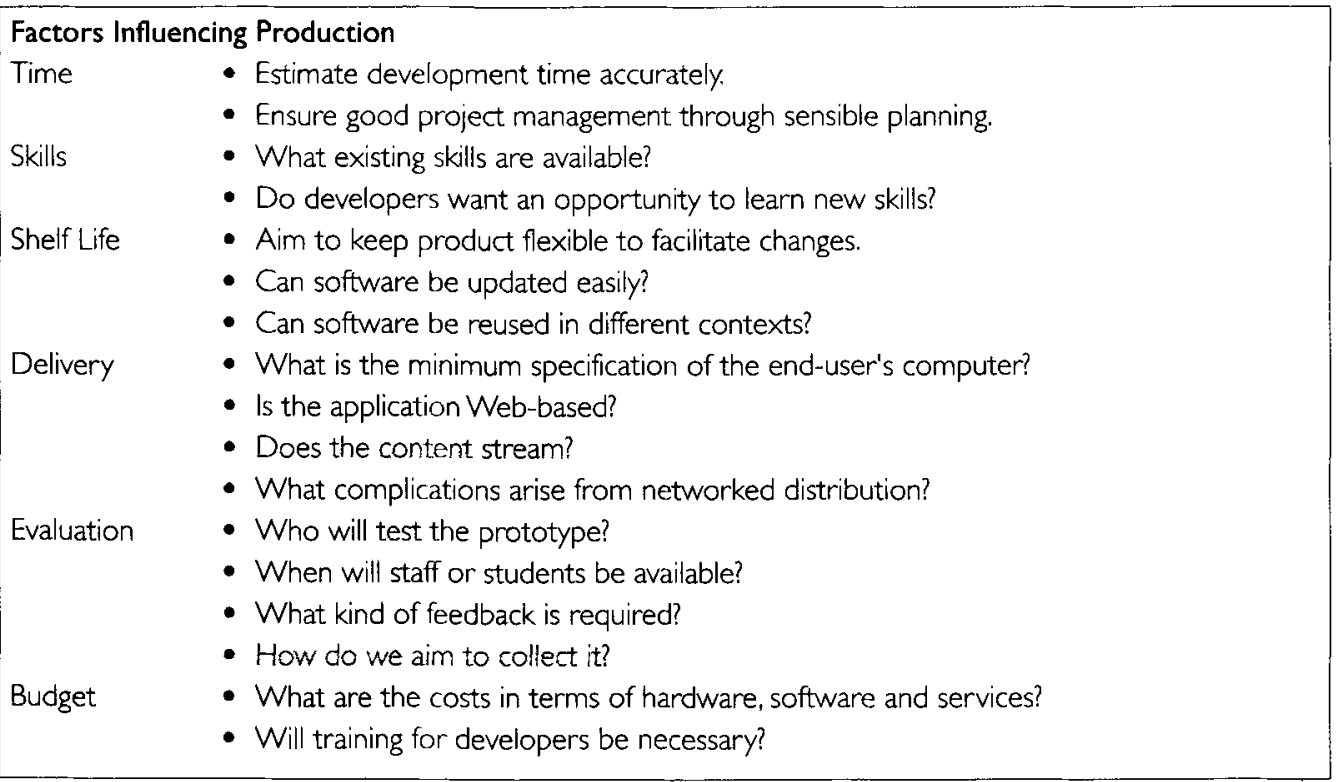

Table 2: Factors influencing the development life cycle.

\section{Interface design}

A good interface enables the user to engage with and control the information presented by the computer. Mullet and Sano (1995) claim that users will discard any interface that appears boring or confusing, and Mandel (1997) emphasizes the benefits of a seductive design, although for him, navigation is the key to the experience from the user's point of view.

Graham (1998) refers to use of icons, stylistic conventions, consistency and controls in her evaluation of navigational schemes. In designing the interface for the virtual primary 
school, the intention was that it should at all times be clear to the user what actions can be taken, without the need to resort to a user manual. In order to facilitate ease of use, a number of principles were considered, which can be categorized as follows:

- Consistency. In order that the user should quickly become familiar with the completed interface design, the design should be consistent across all screens of the implementation. Users will then be able to build an accurate mental model of how the system works (Ambler, 1998). One of Mandel's golden rules (1997) is to reduce the load on the user's memory by relying on recognition rather than recall, and by contextualizing and organizing information.

- Simplicity. An economical style is an elegant solution to the problem of interface design. When it is effective, use becomes transparent and the design itself disappears the ultimate reality for the user becomes the representation (Laurel, 1993).

- Changes of state. Jones and Oakey (1995) define changes in state as effects used to provide users with a cue that a particular action is taking place. In order to avoid the user gaining the impression that their mouse-click has not been recognized, or that the computer has ceased to function correctly, it is important to provide immediate feedback for each user action. This could take the form of a cursor shape change, a sound or the opening of a new window. If there is to be a delay at any time, there should be reassurance in the form of an indication that the user must wait.

- Metaphors. A software interface metaphor is an emulation of a real life system or model to allow the user to act intuitively with that software. Microsoft Windows, for example, uses a desktop metaphor, allowing the user's onscreen workspace to contain files, folders, documents, a trash can and so on. Such features provide clear affordances (that is, the perceived properties of the objects) that are easily understood by the user (Norman, 1992). By using a metaphor with which the user is already familiar, the interface designer aims to maximize the user's understanding of how the interface might function. The interface designed and implemented in Allsorts Primary uses a map metaphor. The user is presented with a plan of the school layout. By clicking on a particular classroom, the user is taken to that room, and allowed to explore it. As the target user group are is fairly well defined, we feel (subject to testing) that this metaphor will prove to be intuitive.

- Colour. When using colour within a user interface, it is important to be aware of users' preconceptions. Although there can be some cultural variation, certain colours have recognized meanings or moods attached to them (Shneiderman, 1992). For this reason, red and green have been used where confirmatory choices are to be made, green being used to reinforce 'yes' or 'ok', red reinforcing 'no' or 'cancel'. The way in which the human eye perceives and absorbs colour information is also an important consideration for the interface designer. We have avoided text and background colour combinations such as red/blue, yellow/purple and magenta/green as they are difficult to read.

- Accessibility. Equality of opportunity and accessibility for all students is important. Alternatives to some media-rich online materials should be provided for students who have auditory or visual impairment. In our case, this involves providing subtitles for 
video interviews and providing a text-based equivalent for the visual interactive presentation.

\section{Programming variables}

Essentially, the software developer has to deconstruct the user's experience (as described in the specification of the application above) into a set of functions and blocks of data, in order to specify the components that will be used to build a virtual model.

Modern software design uses an object-orientated paradigm, aiming to create discrete modules that work together, but can be updated independently. This principle extends to the separation of data and functionality, in order to keep programming code reusable in a variety of contexts. For the model of the school, we identified the following as variables:

- available resources - hardware and software;

- staff - their skills and attitudes;

- current management plans and budget;

- rooms - fittings, furniture, children's work etc.

The user controls the presentation of information in various media, thus the GUI (graphical user interface) provides the main functionality. The user does not input data, so the computer performs no calculations in this prototype. At a later stage we hope to build a more sophisticated model that can randomly generate a school from a limited set of variables.

\section{Virtual reality and multimedia}

'The notion of virtual reality is a continuum that is older even than science fiction' (Laurel 1993: 189). Ghost stories told round the campfire, Ancient Greek dramas and Playstations all share a common goal, which is to heighten audience experience through multi-sensory representation. Our cognitive and perceptual systems are capable of receiving input simultaneously from different senses. While a many-coded meaning is stronger and more memorable than one that derives from only one sense (Gross, 1987), repeated stimulation usually dulls the senses into habituation, suggesting that a degree of restraint is in order. In developing Allsorts Primary, we aim to simulate for the trainee the experience of being an ICT co-ordinator. Laurillard defines a simulation as a model of an aspect of the world which allows the user to make some input, run the model and then display the result (1993: 132). Laurel (1993) and Murray (1997) envisage the computer as an interactive immersive environment, choreographed like a piece of theatre and incorporating multimedia elements and intelligent agents to help the user role-play and explore a virtual world. Our virtual school is essentially a sophisticated presentation, in which the choice of media should contribute to the trainees' engagement with the software and consequent motivation.

\section{Which media?}

Choice of delivery methods is an important factor early in the development life cycle, in our case largely determined by the functionality and shelf life of the proposed software. In order to extend the life and usefulness of Allsorts Primary, it was decided to aim for online delivery, rather than copying the school software to CD-ROM. The advantage of networked distribution is that the resource can be updated or changed and all the users (clients) immediately benefit. 
While Web delivery frees the developer from producing a finite product, it also imposes certain restrictions regarding functionality. Most of these are the result of congestion on the network or narrow bandwidths reducing the speed at which data can be sent or received. The effects are most obvious when presenting a large amount of graphical data, such as video clips or $3 \mathrm{D}$ environments.

When creating the virtual school, we explored the possibility of three-dimensionality on screen. It was felt that $3 \mathrm{D}$ navigation gives a strong sense of engagement with the environment and we looked at several emerging technologies that deliver this experience with varying degrees of success. Cosmo Player and Anfy3D delivers VRML content at high resolution but require the user to download a player to their computer. The VRML files are too large for home users to view quickly, but 3DML can be delivered much faster using the Flatland Rover 2 plugin. However, the format only allows for one item per 256 pixel cube. This means that detail is limited and therefore not suitable for our classroom environments. Shout3D applets deliver Java3D, which looks good but offers limited interactivity.

In order to try these technologies, the classroom was initially modeled in $3 \mathrm{D}$ Studio so that it could be exported as a 3D file. An alternative would be to use actual video footage of a real school. However, navigation then potentially becomes a problem. As the content of every video clip is predetermined, users inevitably become more passive. Another drawback is file size - the quality of video required to show sufficient detail would take too long to download over the Internet.

Our compromise was to build an interactive panorama, a commonly used device for presenting virtual tours of places and buildings. Each space is viewed from a central point with the camera eye seeming to rotate 360 degrees. The user controls the direction and magnification and can move from one panorama to another via hot links. Relevant objects can become hot areas, so that they (in our case, hardware devices) can be clicked to reveal more information. A soundtrack can also be added to each classroom. The panorama is built from a 360 degree flat graphical representation of the classroom (see Figure 3), presented as a HotMedia applet embedded in a Web page.

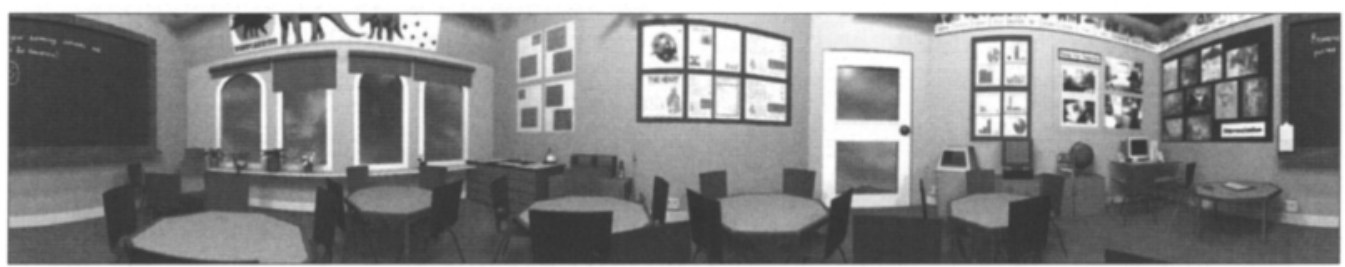

Figure 3: 360 degree panoramic jpeg image.

The time taken to develop the initial 3D model was slightly underestimated, although subsequent classrooms could be more quickly developed as many of the resources have already been created and can be reused. However, on reflection, we have decided to create the rest of the Allsorts environment using panoramic photographs taken on the premises of a real primary school. This is mainly to save time, but also because we felt that we were not able to exploit fully the three-dimensionality online. A drawback may be the cost of hiring suitable camera equipment and software. 
It was felt that for the sake of realism, the interviews would need to be video, rather than audio presented with a photograph, or animation. Three main technologies dominate Web video delivery - RealMedia, Apple Quicktime and Windows Media. While RealMedia and Quicktime work cross-platform, each requires the purchase and implementation of server software to stream the data effectively. Microsoft's Windows Streaming Server is free, except that like the others, it uses up the provider's bandwidth and requires a dedicated machine. Cost will eventually be the over-riding factor, but for our initial prototype we have used RealMedia and Quicktime. The RealPlayer is a standard plugin on most modern computers and can deliver synchronized multimedia integration language (SMIL), which enables a transcript of the teacher's answer to be delivered in RealText simultaneously with the appropriate video clip. The interview streams and plays in real time. Users can then scroll to different sections to replay.

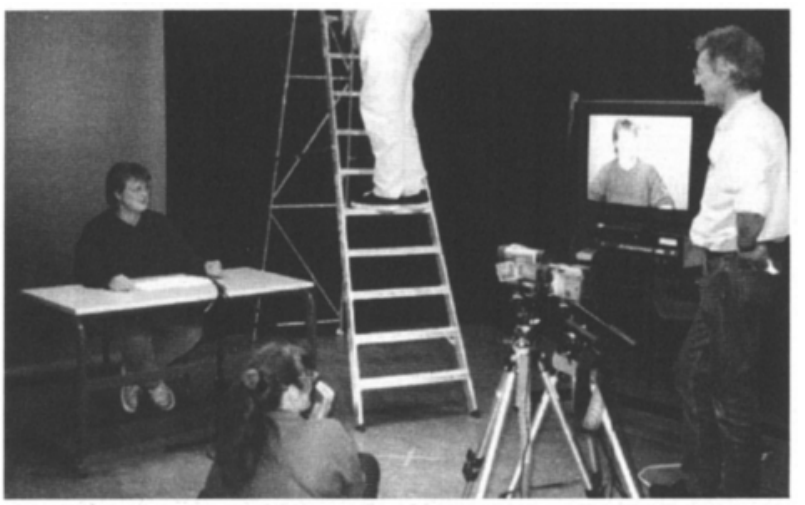

Figure 4: Filming in the television studios.

The Quicktime version utilizes a plugin embedded on a Web page. The list of interview questions is presented in HTML with buttons that launch the relevant answer movie clip.

The first virtual teacher was filmed in the University of North London television studios against a blue screen background. The profile of the character had been prepared and a script of answers was available, although we were hoping for a spontaneous approach by the actor. In the editing phase, the blue screen was removed and replaced with a still from the virtual classroom, giving the impression that the teacher is part of the scene.

It is worth noting the number of people required to make a small-scale video, as well as the hardware and space provision. Figure 4 shows an interview being filmed in the studio; participants include the actress playing the teacher's role, the script-writer/prompter, the director, the camera-person and lighting crew. Post-production time involving capturing and editing is also significant.

The fictional documentation to accompany the software consisted of the following:

- a recent OFSTED report;

- a scheme of work showing an overview of progression and continuity across and through the years;

- a school IT Policy document;

- information about the aims of the software and instructions on how to use the resources. 
We felt it was important to maintain the material in its original paper-based format, rather than choosing to deliver it via a computer, in order to enhance the realism. Back-up copies will be available online, either for updating documents or to replace lost ones.

\section{Conclusions}

The development of Allsorts Primary has relied on the collaboration of people with different skill sets, a certain amount of shared knowledge and a shared enthusiasm for technology and innovative educational practice. While the ultimate goal is to produce an effective and motivating resource for tutors and trainees, the process of designing in a team has its own rewards, in terms of cross-fertilization of ideas, growth of knowledge and development of the skills required to realize the concept.

Although the use of technology has many advantages, there are limitations that need to be acknowledged when using such an approach for teaching and learning. The interaction between a virtual teacher and a trainee is shaped by the predetermined questions selected during the design of the resource. Because of this, the data gathered by the trainee is limited to the questions and answers selected by the designer. Additional questions, which are possible during a real interview, are clearly not possible in the virtual school described in this study. Non-verbal communication can be identified through the use of video footage, incorporated within the structure of the resource, but this is limited to the distance and clarity of the images provided. If the images and sound are of sufficiently good quality, it will be possible for the trainees to identify important visual and auditory cues which will enhance the ensuing discussion. Although genuine human interaction involving negotiation and interpersonal relationships is not possible, the application will be integrated within a wider programme where such issues will be addressed.

There are also limitations regarding the reality of the school and the rooms within. Although the visual images provide a representation of a three-dimensional environment, it does not replace the experience of physically exploring an actual school.

Despite these limitations, the application does provide a rich teaching and learning resource which, if used in conjunction with the real-life school experience, combines the strengths of each. For example, a session could focus on particular issues that can then be studied in depth; such a structured class is not possible in the school environment.

The prototype version of Allsorts Primary contains one clearly defined school with an established cast of teachers and fulfils the minimum requirements of the original brief. We hope that eventually each user will have a unique experience, as a more sophisticated program generates a random school from a finite list of variable factors (staff, resources, environment). This means that the user can attempt the simulation again and visit an Allsorts Primary with a completely different set of values and resources. Alternatively, groups of trainees can visit each others' schools and give feedback on each others' reports. At present, all feedback comes from the tutor on submission of the trainee's appraisal of the school, not from the program itself.

This project has followed a typical software development life cycle. The evaluation process has started with our own ongoing assessment of the project and the product, and it will continue as we collect feedback from students and staff at the associated institutions. The 
reflective nature of the process of designing an innovative resource enables this project to become a learning experience for the participants and for others who are contemplating materials development, as we endeavour to make full use of the latest technology in order to deliver a stimulating product.

\section{References}

Ager, R. (1998), Information and Communications Technology in Primary Schools: Children or Computers in Control, London: David Fulton Publishers.

Ambler, S. W. (1998), User Interface Design: Tips and Techniques, Ambysoft Inc., available online at http://www.ambysoft.com/userInterfaceDesign.pdf.

Birch, T. (1995), 'The teacher and the computer: a case study of the everyday issues in one primary school', School Organisation , 15, (1), 43--51.

Briggs, M. (1997), Your Role as Primary School Subject Co-ordinator, London: Hodder and Stoughton.

Gardner, J. (1993), Frames of Mind: The Theory of Multiple Intelligence, London: Fontana Press.

Graham, L. (1998), The Principles of Interactive Design, London: Delmar Publishers Inc.

Gross, R. D. (1987), Psychology - the Science of Mind and Behaviour, London: Hodder and Stoughton.

Harrison, M. (1998), Coordinating Information and Communications Technology across the Primary School, London: Falmer Press.

Jones, M. G. and Oakey, J. R. (1995), Interface Design for Computer-based Learning Environments, Available online at http://www.hbg.psu.edu/bsed/intro/docs/idguidel.

Laurel, B. (1993), Computers as Theatre, New York: Addison-Wesley Publishing Company Laurillard, D. (1994), 'Multimedia and the changing experience of the learner', in Proceedings of APITITE 94 Conference, Milton: APITITE 94 Council, Vol. 1, 19-24.

Laurillard, D. (1993), Rethinking University Teaching - A Framework for the Effective Use of Educational Technology, London: Routledge.

Mandel, T. (1997), The Elements of User Interface Design, New York: John Wiley \& Sons Inc.

Mullet, K. and Sano, D. (1995), Designing Visual Interfaces, New Jersey: Sun Microsystems Inc., Prentice Hall.

Murray, J. H. (1997), Hamlet on the Holodeck, Cambridge, Massachusetts: The MIT Press. Norman, D. A. (1992), Turn Signals are the Facial Expressions of Automobiles, Wokingham: Addison Wesley.

Ramsden, P. (1992), Learning to Teach in Higher Education, London: Routledge. Shneiderman, B. (1992), Designing the User Interface, Harlow: Addison-Wesley. 
Tiffin, J. and Rajasingham, L. (1995), In Search of the Virtual Class: Education in an Information Society, London: Routledge.

Software and plugins

3D

Cosmo Player http://www.cai.com/cosmol

Anfy 3D http://www.anfyteam.com/

Flatland Rover http://www.flatland.com/

Shout 3D http://216.167.72.79/

Video

RealMedia http://www.real.com/

Apple Quicktime http://www.apple.com/quicktime

Windows Media http://windowsmedia.com/mediaguide/defaultalt.asp

Panorama

HotMedia http://www-4.ibm.com/software/net.medial

QTVR

Technologies

SMIL

VRML

http://www.apple.com/quicktime/qtvr/index.html

Java 3D

http://www.w3.org/AudioVideo/

http://web3d.about.com/compute/web3d/cs/vrmlgeneralinfolindex.htm http://java.sun.com/products/java-media/3D/demos/ 